\title{
ENSAIO ETNOBIOGRÁFICO
}

\section{De Volta para Casa: uma etnobiografia de Dona Lica Xukuru}

Marília Nepomuceno Pinheiro ${ }^{\mathrm{a}}$

O objetivo deste ensaio etnobiográfico é apresentar, dar visibilidade, ou dar a ver, a pessoas de fora do Território Indígena Xukuru quem foi Dona Lica. Lica foi e é uma mestra e guardiã de pressupostos culturais de seu povo e de nossos mundos. A detentora de saber Maria José Martins da Silva, Dona Lica Xukuru, liderança representativa do Povo Xukuru de Ororubá que veio a falecer, em meio ao processo de elaboração deste trabalho, em 7 de agosto de 2020 é sujeita significante na história de Xukuru. Dona Lica é Pajé, manejadora de práticas de cura tradicionais de seu povo, e, como ela própria dizia, "conhecedora das plantas medicinais: o dom da natureza sagrada" (Entrevista com Dona Lica, em 27 de outubro de 2019).

Os Xukuru têm seu território localizado no Agreste de Pernambuco, no município de Pesqueira e em cima da Serra do Ororubá. Esse povo viveu sua reelaboração da identidade étnica indígena em momentos de extremo conflito, sobretudo no processo de retomada do seu território, desde a década de 1990. Os Xukuru disputaram por muito tempo as suas terras, que estavam sob a ocupação de fazendei-

a Mestranda do Programa de Pós-Graduação em Antropologia da UFPE. Email: smariliapinheiro@gmail.com. 
ros da região. Durante esse processo a (re)construção e (re)consolidação de sua identidade étnica se deu de maneira destacada entre os indígenas de Pernambuco. Sob a liderança do Cacique Xicão, a terra indígena (TI) foi demarcada (Neves 2005). Em 1998, após o assassinato do Cacique Xicão por um fazendeiro da região (Neves 2005), seu filho Marcos Luidson, hoje conhecido como Cacique Marquinhos, assumiu o cacicado, tendo, no decorrer dos anos seguintes, vivido e proporcionado processos e práticas de (re)construção de identidades.

A noção de 'Práticas de Autoatenção' (Menendéz 2003, 2009; Pires, Neves \& Fialho 2016), enfocando uma dimensão não só de práticas de cura relacionadas à saúde humana e à profilaxia de doenças, num sentido político e comunitário, dentro do território, e entre seu povo, em processo de autoatenção política entre a comunidade indígena, é uma noção valorosa para este trabalho pois evidencia também a biografia de Dona Lica Xukuru enquanto liderança capaz de articular o diálogo entre os saberes tradicionais Xukuru e as práticas de cura hegemônicas em saúde não indígena. Dona Lica foi em vida referência junto às práticas de autoatenção do corpo-território e à cura capaz de articular uma forma de reforço à identidade de seu povo. E a partir do caminho de sua biografia é possível ver como se deu esse processo de (re)afirmação étnica em Xukuru por meio de suas memórias, do manejo das plantas medicinais e de suas práticas de autoatenção comunitária.

A sua biografia individual figura como emblema coletivo (Pollak 1989), e sua morte impacta esse mosaico (Candau 2017) do repertório coletivo de seu povo. Afinal de contas, a memória coletiva e individual são construções que dialogam, sobretudo enquanto narrativa da memória e não como história oficial, amplamente explorado por Maurice Halbwachs em Memória, Esquecimento, Silêncio (Pollak 1989).

Na ocasião do Encontro de Pajés e Parteiras do Estado de Pernambuco 2019 - evento organizado pelo Distrito Sanitário Especial Indígena (DSEI) no território Truká em Cabrobó-PE, entre os dias 24 a 28 de outubro de 2019, tive a oportunidade de perceber a sua desen- 
voltura como liderança religiosa preocupada com a grande incidência de depressão dentro de seu território e como as práticas de cura indígenas podiam incidir para sanar essa doença e acometimento trazido do mundo dos brancos aos indígenas. Dona Lica chamava muita atenção, pois era uma mulher ocupando um lugar majoritariamente ocupado por homens. E, além disso, destacava-se por ser de uma geração mais antiga e estar sempre acompanhada, rodeada e articulada, com indígenas da juventude, fomentando um diálogo intergeracional entre seu povo. Esses marcadores sociais da diferença, como gênero e geração, assumiram contornos que chamam a atenção na produção de saber por Dona Lica.

Diante dessa potência é que se faz o motivo da exposição fotográfica Etnografia visual e biográfica de Dona Lica Xukuru (www. instagram. com/caminhodevoltaparacasa) que lança luz tanto ao caminho em que as fotografias foram feitas, no caminho de volta para casa depois de um dia de trabalho como auxiliar de farmácia no Polo Base Xukuru, em Março de 2020; como também faz referência ao caminho feito por Dona Lica em sua trajetória de vida enquanto liderança e mulher indígena, fazendo questão de narrar e trazer à tona as práticas de retorno à tradição, junto às plantas e ervas medicinais, para tratar e curar as doenças e acometimentos vividos pelos indígenas Xukuru em lugar de somente manejar os remédios 'do branco', como ela mesmo nomeava, oferecidos em farmácias - seu local de trabalho. O caminho 'de volta para casa' também faz referência ao evento da morte, do 'encantamento', de Dona Lica do plano de vida material, e onde jaz o seu corpo plantado na mata sagrada da Pedra D'água - reinado encantado Xukuru, para onde vão/retornam todas as figuras de referência de seu povo.

Dona Lica Xukuru, Pajé e manejadora de práticas de cura tradicionais de seu povo, é detentora de saber tradicional - categoria e denominação relacionada a sujeitos detentores de saberes e práticas tradicionais em seus territórios enquanto patrimônios imateriais, utilizada pelo Iphan para se referir aos brincantes, fazedores ou portado- 
res dos saberes, conhecimentos, técnicas e sentidos relacionados ao bem (Alencar 2017).

Entendendo que além de ser uma detentora de memórias e saber tradicional, Lica Xukuru manejava e foi criadora de práticas de autoatenção junto a seu povo, é importante pensarmos junto ao Eduardo Menendéz $(2003,2009)$ quando entendemos que as 'Práticas de Autoatenção' são uma noção que considera aspectos sociais, culturais e econômicos, e faz referência ao universo de práticas em busca por cura, relacionando-se com os conceitos de 'autocuidado'. Nesse sentido, a autoatenção vivenciada em Xukuru, e por meio da biografia da própria Dona Lica, compreende desde o processo de retomada territorial e étnica, como a promoção de eventos, discussões e pleitos políticos em busca de seu autocuidado comunitário, como se dá a partir da promoção e consolidação de estratégias e práticas próprias, que podem ser lidas como sua 'automedicação política'. Podemos tomar como exemplo dessa automedicação política e autocuidado comunitário a instauração, por exemplo, do processo judicial na Corte Interamericana de Direitos Humanos (CIDH) que demandou o reconhecimento, a titularidade e a demarcação de suas terras. O 'autocuidado político e comunitário’ em sentido amplo aqui engloba aspectos que vão desde a luta pela terra às práticas da saúde indígena no território - onde o corpo e a terra se entrecruzam e geram o entendimento de saúde e medicina natural em Xukuru. Autoatenção se faz de um conjunto que determina as relações entre saúde/enfermidade/atenção e reflete formas que asseguram a reprodução social dos sujeitos, envolvendo relações familiares, distribuição de alimentos, o ambiente em que se vive, a relação com a morte, os rituais, o uso sustentável da água etc (Pires, Neves \& Fialho 2016).

Vânia Fialho (2016), ao elencar também a noção de 'Autoatenção' de Menéndez (2003, 2009) traz a compreensão da relação entre os saberes tradicionais e a biomedicina, a partir da experiência do povo Xukuru em seu território, traçando os diálogos entre antropologia e saúde. A antropóloga destaca que os povos indígenas não são agentes 
passivos no cenário da saúde, mas atuam em conjunto com o sistema de saúde, assim como também agem fora do sistema oficial, ocidental, de cura. "Ao longo dos anos Xukuru têm investido na formação biomédica de seus quadros, de forma que alguns técnicos e auxiliares de enfermagem são indígenas" (Pires, Neves \& Fialho 2016:241). Além disso, elenca que Xukuru promoveu encontros, desde 2006, com objetivos claros de discutir saúde com a interlocução dos curadores tradicionais de seu povo e as EMSI - Equipes Multidisciplinares de Saúde Indígena, com foco nas plantas medicinais, 'medicina natural' e 'remédios do mato', em que se circunscreve especificamente a atuação de Dona Lica.

"Identificamos uma atenção com a 'medicina natural', como chamada pelos Xukuru, e que pode ser pensada em um sentido mais amplo do termo, ou seja, a 'medicina natural' é uma categoria que envolve as práticas culturais de alimentação, o controle dos recursos hídricos, e o uso das plantas medicinais, o que corrobora com o conceito de saúde proposto por Eduardo Menendéz (2003 e 2009)" (Pires, Neves \& Fialho 2016:244).

É nesse cenário e diante dessa compreensão do povo Xukuru que está inscrita Dona Lica. Sendo uma das indígenas a buscar formação na biomedicina e ser em simultâneo sujeito indígena responsável pelo retorno do uso dos remédios do mato e à saúde natural.

Em conversa com Cristiano Jerônimo, Cris Xukuru, jovem indígena que partilhava com Dona Lica vivências no local de trabalho, o Polo Base Xukuru, e também em momentos de rituais, fica evidente como a trajetória de Dona Lica é um retrato do processo de Autoatenção e (re)elaboração e constituição identitária vivido em território Xukuru ao longo dos anos. Referindo-se a Dona Lica como grande livro vivo, ele relata:

Dona Lica quando entrou na saúde era agente de saúde no tempo do PACS na Aldeia Cana Brava. Dona Lica subia essas serras a pé pra ir prestar assistência do serviço dela na Aldeia Cana Brava. Dona Lica passou pra FUNAI, pra FUNASA, aí Dona Lica fez um curso de técnico de enfermagem pela UFPE e entrou pela função 
de serviço para trabalhar na área da farmácia, como auxiliar farmacêutica. Foi o que ela mais queria. Enquanto as pessoas implantavam a questão das medicação do branco, Dona Lica questionava que as pessoas da comunidade fizesse o uso da medicação tradicional. Se você chegasse lá na farmácia e pedisse a Dona Lica uma medicação, um anti-inflamatório, ela vinha indicar e falava uma medicação tradicional, uma erva, uma quixabeira, cajueiro roxo, seja lá que tipo de erva fosse, que servisse no lugar daquela medicação que o parente indígena queria, que era a medicação branca. Ela tentava desconstruir e vinha desconstruindo essa visão que às vezes tinha na comunidade, que as pessoas tão criando uma crença que só se cura se for através da medicação do não-índio, né, da medicação branca e ela vinha desconstruindo essa visão. Mas infelizmente fez a passagem da vida dela... Se você tivesse noção da quantidade de informação que Dona Lica deixou dentro do povo Xukuru, não é brincadeira. Não existe livro que possa escrever; não existe. Eu acho que todo evento do povo Xukuru quando se tratava de apresentações sobre ervas medicinais, já era Dona Lica. Religião, era Dona Lica. Falar sobre questão de crença, de uma forma de oração, era Dona Lica. (Cristiano Jerônimo, indígena Xukuru em conversa gravada sobre essa exposição, em 10 de outubro de 2020).

Dona Lica fez de sua trajetória uma 'Simbiose' - noção elencada por Elaine Müller (2020) - que compreende a prática e atuação das parteiras tradicionais brasileiras que estabelecem relações empáticas e profundas com seus 'pacientes' ou 'clientes' e sua comunidade entre seus saberes ancestrais e tradicionais e o que foi apreendido por elas nos sistemas de conhecimento hegemônico fomentado pela biomedicina. Ocupando local de referência no lugar de cuidado em saúde, o que torna muito oportuno para pensar as práticas e condutas de Dona Lica Xukuru por meio dessa mesma noção de 'simbiose' enquanto Pajé. A simbiose de Lica Xukuru entre os saberes tradicionais de seu povo e o aprendido no universo da biomedicina, evocando a noção de 'Intermedicalidade', conceito utilizado por Foóler (2004) a partir de uma concepção de Greene (1998), em que se compreende a zona que a biomedicina se relaciona com outros saberes não médicos tanto na teoria quanto na prática, assim como a noção de 'Pluralidade Terapêutica', que compreende como os indígenas geraram a necessidade 
de conhecer outros sistemas terapêuticos (Fialho 1992), podem ser aplicados ao diálogo feito por Dona Lica em sua trajetória de vida e biografia. Lica Xukuru buscou formação na área da biomedicina e foi capaz de tecer um diálogo com as práticas tradicionais de cura de seu povo, entre tratamentos e curas com plantas medicinais e rezas, promovendo encontro de saberes dentro do universo da atenção à saúde, trazendo à tona este diálogo de práticas de autoatenção, e um diálogo intenso entre cultura e saúde. A Simbiose e Práticas de Autoatenção Comunitária praticadas por Lica Xukuru são um valioso bem cultural capaz de lançar luz aos pressupostos coletivos de seu povo e como os Xukuru vêem e se relacionam com o mundo.

Evidenciar práticas e saberes de Lica Xukuru relacionados às plantas e ervas medicinais, sem adentrar ao universo das rezas onde ela era extremamente ativa também, se fez escolha pelo seguinte motivo: tematizar as rezas foi sempre algo que Dona Lica preferiu não fazer para o mundo dos não-indígenas, e é o que nos possibilita ler como as memórias trazidas por Dona Lica até os dias de hoje são memórias que Michael Pollak (1989) chama de 'memórias subterrâneas'. As memórias subterrâneas em sua maioria estão ligadas a fenômenos de dominação ou conflito, que precisaram ou foram obrigadas a ser escondidas da memória oficial e da história. Para Pollak,

"A fronteira entre o dizível e o indizível separa uma memória coletiva da sociedade civil dominada ou de grupos específicos, de uma memória coletiva organizada que resume a imagem que uma sociedade majoritária ou Estado desejaram passar e impor. Distinguir entre conjunturas favoráveis ou desfavoráveis às memórias marginalizadas é de saída reconhecer a que ponto o presente colore o passado. Conforme as circunstâncias, ocorre a emergência de certas lembranças e a ênfase é dada a um ou outro aspecto" (Pollak 1989:6).

Evidenciando com isso a permanente interação entre o vivido e o aprendido e o vivido e o transmitido, que Gabriele Rosenthal em seu artigo História de vida vivenciada e história de vida narrada também vai se tematizar para nos ajudar a refletir sobre a relação que uma pesquisa com enfoque biográfico é capaz de mobilizar diante das perspectivas 
subjetivas dos agentes do cotidiano e o quanto de suas histórias de ação estão entrelaçadas com o universo social. Rosenthal (2014) nos traz a noção dos 'fluxos recordativos' presentes em situações de pesquisas biográficas, e que nesse fluxo o futuro é projetado de maneira nova e o passado (re)interpretado.

"As narrativas de experiências feitas pela própria pessoa remetem tanto à vida atual com esse passado quanto à experiência ocorrida no passado. [...] E, assim, narrativas biográficas informam tanto sobre o presente dos narradores quanto seu passado e sua perspectiva em relação ao futuro" (Rosenthal 2014:21).

O que está em jogo na memória é também o sentido da identidade individual e do grupo. Esse trabalho de gestão da memória (Pollak 1989) foi algo empreendido por Dona Lica em vida para o trabalho que pensamos juntas. Como escreve Pollack no trecho: "No momento em que testemunhas oculares sabem que vão desaparecer em breve, elas querem inscrever suas lembranças contra o esquecimento" (Pollak 1989:3). O fluxo memorial (Candau 2017) que se deixa ser visto neste trabalho é, portanto, uma conjunção original e constitutiva do contexto político e social específico a que Dona Lica estava imersa em vida.

Dona Lica se reconhecia como alguém responsável pela circulação de saberes tradicionais e ancestrais de seu povo, e este reconhecimento tinha também entre seus pares. Relatava com muito afinco que havia sido escolhida pelo seu irmão Pajé Zequinha, de idade mais avançada, para lhe substituir na missão de ser Pajé do Povo Xukuru, e por isso estava há anos sendo preparada.

Eu sou Lica do povo Xukuru do Ororubá. Sou irmã do Pajé Zequinha, de quem eu recebi o prazer dele passar o dom, a missão dele dentro do Povo Xukuru como Pajé. E eu vejo dentro do Povo Xukuru, o povo me acolhe com muito amor, com muito carinho, assim como eu também tenho muito amor a dar ao meu povo que são meu sangue. Se eu for ignorar meu povo, eu to ignorando própria a mim, então eu tenho um amor muito grande pelo meu povo Xukuru. Os jovens, de quem eu aparo mais; também os mais 
velhos de quem eu respeito, tenho a consideração de todos. (Entrevista com Dona Lica em outubro de 2019, no encontro de Pajés e Parteiras indígenas do Estado de Pernambuco).

Imersa no processo junto a Dona Lica, fui impregnada pelo universo de Dona Maria José Martins da Silva, Lica Xukuru, diante do manejo de plantas e ervas de cura, e em conversa nossa surgiu a ideia de que poderíamos contar essas memórias e uma história através de imagens: contar a sua história.

Uma comunicação desprovida de intencionalidade científica ou de pesquisa capaz de revelar e partilhar dimensões de conhecimentos que um/uma etnógrafo/a dificilmente acessaria de outra maneira foi sem dúvidas um elemento chave para o nosso encontro. Ser afetada, como nos diz Favret-Saada (2015), é ser afetada no sentido de se permitir às razões do outro, os sentidos do outro. Captar e se permitir isso. E, não tem a ver com 'empatia' - termo que se refere a 'tolerar' ou 'respeitar'. Tem a ver com ser envolvido. É, portanto, uma ênfase à prática de pesquisa da/o antropóloga/o em campo, da mesma maneira que faz da escrita sobre o campo uma ferramenta regida a partir de um olhar sensível e analítico sobre as experiências, a fim de desenvolver um olhar de forma específica para o que foi vivido.

Para elucidar quem foi Dona Lica e como era figura marcante, lhes trago novamente um trecho de fala de Cristiano Jerônimo, Cris Xukuru, que apresenta Dona Lica de maneira especial, como "liderança religiosa, pajé e professora”:

Trabalho sob direção do polo base, que é uma unidade de saúde que tem ressocialidade geral com todo o contexto de saúde do povo Xukuru. E ali tem várias dirigências, e especificamente a farmácia... A farmácia era o setor de trabalho de Dona Lica, a senhora Maria José Martins da Silva, conhecida por Lica. Minha liderança religiosa, minha amiga, mãe, companheira de luta, companheira de todos os momentos. Até o presente momento é difícil a gente sempre falar de Dona Lica, porque sempre lembra os momentos que a gente teve juntos nessa trajetória de luta, do dia a dia. Então Dona Lica é uma pessoa especial, Dona Lica é uma pessoa alegre, uma pessoa brincalhona, em momento sério, uma professora, na verdade. Sem- 
pre tinha sua forma de ensinar e apresentar seus ensinamentos, amostrar os seus conhecimentos sobre ervas medicinais, sobre o momento de espiritualidade... Como se trabalhar no ritual, no toré sagrado. Dona Lica ela tem uma importância muito grande no povo Xukuru no momento do ritual que Dona Lica que faz abertura, ou seja, o que a gente chama de pajelança. Enquanto Dona Lica não abrisse aquela pajelança o ritual não começava, e para terminar do mesmo jeito. A gente tem por exemplo o nosso Dia de Reis. Dona Lica fazia pajelança de início do Dia de Reis. Dona Lica num determinado momento já não tava mais no terreiro com a gente, ela já tava em cima da Pedra do reino que só se sobe uma vez no ano... Ela já tava esperando os guerreiros lá, e para subir naquele momento ali naquela pedra para aquele ritual específico só sobe aquelas pessoas que são indicadas pela pessoa religiosa dela. Que é um momento espírita, um momento privado, é um momento bastante religioso. Dona Lica sempre nos ensinava através dela e da visão dela com lado espiritual a gente tinha informação de como ver o dia seguinte, como é que ia ser o ano, o que é que a gente tinha que fazer para mudar se a gente tava errado, se a gente tava certo... (Cristiano Jerônimo, indígena Xukuru em entrevista gravada em 10 de outubro de 2020).

Contar, através de fotografias ou de um pequeno texto, sobre Lica Xukuru e suas memórias é algo muito significativo numa sociedade em que mestras e mestres, detentores e guardiões de bens e pressupostos culturais de nosso povo foram sistematicamente invisibilizados de grande parte da vida e do imaginário da/o brasileira/o comum, e da história oficial. Sobretudo se tratando de sujeitos indígenas que a historiografia oficial lhes negou o protagonismo da resistência indígena à colonização, e as abordagens de rearranjamento das suas tradições, tomadas tanto pelos indígenas quanto pela população negra, para manterem-se vivos até os dias de hoje (Milanez et al 2019). Numa sociedade desigual e diversa como a brasileira, a cultura, a memória e a visibilização de patrimônios imateriais e detentores de saberes e bens culturais tornaram-se caminhos que elucidam e indicam a importância desses sujeitos em nossa sociedade, mostrando-se capaz de nos lembrar que esses guardiões de pressupostos culturais são sujeitos ativos dentro do mundo que existimos, e estão - sem cessar - produzin- 
do resistências, diálogos e soluções para o mundo. Além de ser capaz também de assegurar direitos, em últimas instâncias. Candau vai bem nos dizer que "nossa memória não tem a função de estocar nossas experiências do passado, mas de reciclar seus constituintes, recombinando-os para imaginar e preparar o futuro" (2017:843). Os processos memoriais coletivos e as políticas de memórias entre os povos historicamente violentados implicam no esforço para, tirando lições do passado, garantirmos um futuro isento de tragédias. Enquanto uma inscrição no futuro, essa gestão memorial, ontologiza a partilha da memória (Candau 2017).

A exposição de fotografia que sonhamos é, portanto, o encontro entre diversos suportes de memória, e também um encontro de atravessamentos de memórias de pessoas sobre a vida e os conhecimentos de Lica Xukuru. Sejam elas advindas da história de vida narrada pela própria Lica, sejam elas advindas da elaboração de memória de seu povo, ou sejam elas advindas do registro fotográfico e da organização de minhas memórias em campo.

\section{Referências:}

ALENCAR, Rívia (ed.). 2017. Salvaguarda de bens registrados: patrimônio cultural do Brasil: apoio e fomento / coordenação e organização. Brasília: IPHAN.

CANDAU, Joël. 2017. "A memória e o princípio de perda”. Diálogos, 16(3):843872.

FAVRET-SAADA, Jeanne. 2005. "Ser afetado”. Cadernos de Campo, 13:155-161.

FIALHO, Vânia R. 1992. As fronteiras do ser xukuru: estratégias e conflitos de um grupo indígena no Nordeste. Dissertação de Mestrado. Recife: Universidade Federal de Pernambuco. (https://repositorio.ufpe.br/handle/123456789/16967; acesso em 03/11/20).

FOOLÉR, Maj-Lis. 2004. "Intermedicalidade: a zona de contato criada por novos indígenas e profissionais de saúde". In LANGDON, E. \& GARNELO, L. (eds.): Saúde dos povos indígenas: reflexões sobre a antropologia participativa, pp. 129-147. Rio de Janeiro: Contra Capa/ABA.

GREENE, Shane. 1998. “The Shaman's needle: development, shamanic agency, and intermedicality in Aguaruna Lands, Peru". American Ethnologist, 25(4):634-658. 
MENENDEZ, Eduardo L. 2003. "Modelos de atención de los padecimentos: de exclusiones teóricas y articulaciones prácticas". Ciência e Saúde Coletiva, 8(1): 185-207.

. 2009. Sujeitos, Saberes e Estruturas: uma introdução ao enfoque relacional no estudo da saúde coletiva. São Paulo: Ed. HUCITEC.

MILANEZ, F. et al. 2019. "Existência e diferença: o racismo contra os povos indígenas". Revista Direito e Práxis, 10(3):2161-2181.

MÜLLER, Elaine. 2020. A parteira faz Simbiose: a parteira tradicional e os campos de saberes. Trabalho apresentado na $32^{a}$ Reunião Brasileira de Antropologia, Rio de Janeiro-RJ.

NEVES, Rita C. M. 2005. Dramas e Performances: o processo de reelaboração étnica Xukuru nos rituais, festas e conflitos. Tese de Doutorado. Florianópolis: Universidade Federal de Santa Catarina.

PIRES, M. J., NEVES, R. C. \& FIALHO, V. 2016. "Saberes Tradicionais e Biomedicina: reflexões a partir da experiência dos Xukuru do Ororubá, PE”. Revista Anthropológicas, 27(2):240-262.

POLLAK, Michael. 1989. "Memória, esquecimento, silêncio". Revista Estudos Históricos, 2(3):3-15.

ROSENTHAL, Gabriele. 2014. "História de vida vivenciada e história de vida narrada: A interrelação entre experiência, recordar e narrar”. Civitas - Revista de Ciências Sociais, 14்(2):227-249.

Recebido em junho de 2021.

Aprovado em outubro de 2021. 